\title{
Interprofessional Education at a Distance: The Hybrid Interprofessional Education Model
}

\author{
Melissa J. Lazinski \\ Nova Southeastern University, mr1707@nova.edu \\ Lynda Ross \\ Florida Gulf Coast University, Iross02@spalding.edu \\ Suzanne Wolf \\ Wingate University, s.wolf@wingate.edu \\ Megan Finck \\ Nova Southeastern University, mf1245@nova.edu \\ Lance Cherry \\ Nova Southeastern University, Ic1315@nova.edu
}

Follow this and additional works at: https://nsuworks.nova.edu/ijahsp

Part of the Interprofessional Education Commons, and the Scholarship of Teaching and Learning Commons

\section{Recommended Citation}

Lazinski MJ, Ross L, Wolf S, Finck M, Cherry L. Interprofessional Education at a Distance: The Hybrid Interprofessional Education Model. The Internet Journal of Allied Health Sciences and Practice. 2021 Jan 01;19(3), Article 15.

This Manuscript is brought to you for free and open access by the College of Health Care Sciences at NSUWorks. It has been accepted for inclusion in Internet Journal of Allied Health Sciences and Practice by an authorized editor of NSUWorks. For more information, please contact nsuworks@nova.edu. 


\title{
Interprofessional Education at a Distance: The Hybrid Interprofessional Education Model
}

\begin{abstract}
Background: Interprofessional education (IPE) is a critical component of health professions education but planning and implementation are challenged by logistical, physical, personnel, and recently global pandemic COVID-19 barriers. Purpose: This report describes the development and design of the proposed Hybrid Interprofessional Education (HIPE) model, a blended learning IPE model developed to mitigate barriers using a flexible framework and online collaborative technologies to deliver experiences based on Interprofessional Education Collaborative (IPEC) core competencies. Operational principles, model design, an example of model implementation, and outcomes are reported. Method: Fifty-four student physical therapists and physician assistants attending remote campuses of the same university participated and completed an exit survey. Descriptive statistics were calculated for Likert scale and semantic differential scale survey items and thematic analysis was conducted for open question responses. Results: Analysis revealed students felt improved understanding of interprofessional practice, the other profession's role, teamwork, and communication. Responses supported online, asynchronous delivery and the web application used but not the synchronous activity portion. Three themes arose from comments: learning with and from, interactions, and activity design. Conclusion: The HIPE model was used to deliver IPE that supported perceptions of student learning in IPEC core competencies when physical proximity was not possible. Further iterative research and model refinement are needed. Future research should include investigation of student learning outcomes when using the HIPE model.
\end{abstract}

\section{Author Bio(s)}

Melissa J. Lazinski, PT, DPT, DHSc is an Associate Professor in the Department of Physical Therapy at Nova Southeastern University in Clearwater, FL. She is also a licensed physical therapist specializing in orthopedics.

Lynda Ross, PT, DPT, DHS is an Assistant Professor in the Department of Rehabilitation Sciences at Florida Gulf Coast University in Ft Meyers, FL. She is also a licensed physical therapist specializing in pediatrics and neurological physical therapy.

Suzanne "Suzie" Wolf, MS PAS, PA-C is the Director of the Public Health Program and Assistant Professor in Physician Assistant Studies at Wingate University in Wingate, NC. She is also an adjunct professor for the Physician Assistant Program at Nova Southeastern University in Jacksonville, FL.

Megan Finck, MMS, PA-C is an Assistant Professor in the Department of Physician Assistant at Nova Southeastern University in Jacksonville, FL. She is also a licensed physician assistant.

Lance Cherry, PT, MPT, EdD, is an Associated Professor in the Department of Physical Therapy at Nova Southeastern University in Clearwater, FL. $\mathrm{He}$ is also a licensed physical therapist specializing in orthopedics.

\section{Acknowledgements}

The authors would like to acknowledge Melissa Moran Tovin, PT, MA, PhD for her consultation in the thematic analysis. Dr. Tovin has given permission to this acknowledgement. 


\title{
1IJAHSP \\ The Internet Joumnal of Allied Health Sciences and Practice \\ Vol. 19 No. 3 ISSN 1540-580X
}

\section{Interprofessional Education at a Distance: The Hybrid Interprofessional Education Model}

\author{
Melissa J. Lazinski ${ }^{1}$ \\ Lynda Ross ${ }^{2}$ \\ Suzanne Wolf3 \\ Megan Finck ${ }^{1}$ \\ Lance Cherry ${ }^{1}$
}

1. Nova Southeastern University

2. Florida Gulf Coast University

3. Wingate University

United States

\begin{abstract}
Background: Interprofessional education (IPE) is a critical component of health professions education but planning and implementation are challenged by logistical, physical, personnel, and recently global pandemic COVID-19 barriers. Purpose: This report describes the development and design of the proposed Hybrid Interprofessional Education (HIPE) model, a blended learning IPE model developed to mitigate barriers using a flexible framework and online collaborative technologies to deliver experiences based on Interprofessional Education Collaborative (IPEC) core competencies. Operational principles, model design, an example of model implementation, and outcomes are reported. Method: Fifty-four student physical therapists and physician assistants attending remote campuses of the same university participated and completed an exit survey. Descriptive statistics were calculated for Likert scale and semantic differential scale survey items and thematic analysis was conducted for open question responses. Results: Analysis revealed students felt improved understanding of interprofessional practice, the other profession's role, teamwork, and communication. Responses supported online, asynchronous delivery and the web application used but not the synchronous activity portion. Three themes arose from comments: learning with and from, interactions, and activity design. Conclusion: The HIPE model was used to deliver IPE that supported perceptions of student learning in IPEC core competencies when physical proximity was not possible. Further iterative research and model refinement are needed. Future research should include investigation of student learning outcomes when using the HIPE model.
\end{abstract}

Keywords: interprofessional education, interprofessional e-learning, interprofessional distance learning, online interprofessional education, virtual interprofessional education, interprofessional education strategies 


\section{INTRODUCTION}

Interprofessional collaborative practice (IPCP) is recognized as a critical approach to improving patient safety and outcomes, quality of care, and reducing health care costs. ${ }^{1,2}$ Health policy makers identified interprofessional education (IPE) as a chief strategy to cultivate IPCP in future health care professionals. ${ }^{3}$ Academic institutions are required by accrediting agencies to integrate IPE into the curriculum. ${ }^{4}$ Through IPE, students develop characteristics and skills that foster delivery of patient-centered care in a collaborative manner. 1,5 IPE advances students' attitudes, knowledge, and skills toward collaborative practice, strengthens collaborative practice, and improves patient care. ${ }^{1}$

Planning and implementing IPE activities that nurture future clinicians to be collaborative practice-ready is a challenging process. 6,7 Building IPCP competencies requires IPE activities that bring students from 2 or more professions together "to learn about, from and with each other." ${ }^{8}$ Logistical and resource issues such as conflicting program schedules, geographical location, physical space, high faculty workload, and most recently the global COVID-19 pandemic are common barriers to IPE that health professions educators encounter. ${ }^{9} \mathrm{~A}$ blended learning approach may reduce some barriers, but models for implementation of blended IPE in the literature are few. $10,11,12$

Blended or hybrid learning has a number of definitions, but a commonly cited definition describes it as "the thoughtful integration of classroom face-to-face learning experiences with online learning experiences."13 The use of information and communication technologies for IPE can lead to positive attitudinal and knowledge change and favorable reaction to IPE activities delivered in this format. ${ }^{14}$ Effective hybrid learning is supported by instructional design theory or models which define essential elements aimed at achieving a particular outcome. ${ }^{15}$ The question is, can virtual interprofessional education build IPCP competencies?

This report describes the development and design of the proposed Hybrid Interprofessional Education (HIPE) model, a blended learning IPE model. ${ }^{15}$ The aims are to a) describe the model's operational principles, b) describe the model's design, c) present an example of the use of the model in a blended IPE activity with doctor of physical therapy students (SDPTs) and physician assistant students (SPAs), and d) report outcomes in terms of the model's utility, feasibility, and its ability to influence students' perceptions of and attitudes towards IPCP.

\section{BACKGROUND}

The HIPE model was born out of necessity at a hybrid DPT program located at a satellite campus with limited access to other programs with which to collaborate for IPE. In addition, the hybrid format of the program was such that DPT students were only together on campus 4 days per month. The HIPE model was developed to increase access to IPE by mitigating logistical and resource barriers to conducting IPE activities through a flexible framework and online technologies. Three educational frameworks informed the development of the model: a) the Interprofessional Education Collaborative (IPEC) core competencies; $b$ ) the Community of Inquiry (Col) framework, and c) the National League for Nursing (NLN) Jeffries Simulation Framework. ${ }^{12,16,17,18}$

The IPEC defined the core competencies to help educators create robust IPE experiences that prepare future health professionals to effectively collaborate "to build a safer and better, person-centered and community/population-oriented health care system." ${ }^{19}$ IPE activities based on these core competencies teach students the culture of mutual respect and shared values amongst interprofessional team members, roles and responsibilities of other health professionals, responsive and respectful communication skills, and team dynamics and teamwork. ${ }^{16}$

The Col framework was developed as a model to guide educators in creating successful online learning experiences. ${ }^{20}$ The underlying assumption of the Col framework is that learning occurs within a community via interaction of cognitive, social, and teaching presence..$^{20}$ The Col framework fits well with IPE because both require community and collaboration to thrive..$^{12}$ Social presence, the ability to be perceived as real people online, brings students together as health professional community members to collaborate and build team-based skills during IPE activities. ${ }^{17}$ Cognitive presence enables students to "construct and confirm meaning through sustained reflection and discourse," which is needed to gain knowledge, skills, attitudes, and behaviors to function effectively as an interprofessional team member. ${ }^{17}$ Teaching presence and "the design, facilitation, and direction of cognitive and social processes" is required to facilitate discourse between students, direct students towards forming relationships, and change erroneous assumptions such as professional stereotypes during IPE activities. ${ }^{12,17}$

The NLN/Jeffries Simulation Framework is an evidence-based framework used to design human simulation experiences in prelicensure clinical nursing education. ${ }^{21}$ Objectives, student support, problem solving, fidelity, and debriefing are simulation design characteristics described in the NLN/Jeffries Simulation Framework that are incorporated in the pre-brief, simulation activity, and debriefing phases of a simulation experience. ${ }^{22}$ The pre-brief contains the objectives and student support elements that prepare learners for a simulation experience by outlining performance expectations and capabilities of a simulation environment. ${ }^{23,24}$ The 
simulation activity integrates student support (cues), problem solving (complexity), and fidelity (authentic clinical scenarios) into the learning experience. Debriefing after the simulation experience facilitates reflective thinking enabling students to uncover, analyze, and modify their initial frames of reference. ${ }^{23}$

\section{Description of the Hybrid Interprofessional Education (HIPE) Model}

The core attributes of the HIPE model are a) objectives based on IPEC core competencies, b) asynchronous and synchronous modes, c) collaborative communication technologies, d) phased delivery, and e) fidelity/realism.

The HIPE model has 3 main phases, like simulated learning experiences. The first 2 phases, pre-briefing and interprofessional interaction, occur asynchronously (see Figure 1). The third phase, debriefing, occurs synchronously. Pre-briefing is the first step that sets the stage for an activity by explaining roles, expectations, activity parameters, learning objectives based on IPEC core competencies, and provides necessary context related to an IPE clinical scenario. ${ }^{23,24}$ In development of an IPE activity, instructors should work collaboratively to plan the activity well in advance. This includes outlining the activity and determining the contextual pre-briefing topics like introducing students to the case, the involved practice setting, characters, roles, and problems involved. ${ }^{23,24}$ Additional pre-briefing logistical considerations include orienting students to participation expectations or grading, schedules, and collaborative technologies that are involved. Pre-briefing occurs asynchronously through the use of text, audio, or video materials posted for students to review in advance.

In the interprofessional interaction phase, students work together in small interprofessional groups that allow for diversity in perspective, conversation, and discussion in an online asynchronous collaborative workspace akin to a virtual roundtable. The interaction begins with a clinical scenario trigger using rich media, like video. Video allows for fidelity or realism in the depiction of a clinical scenario which is a key principle in simulation credited for driving students' cognitive processes, social dynamics, and emotional responses like those of a true clinical environment. ${ }^{23,24}$ The trigger is accompanied by a prompt directing the small group to interact in some way. For example, students may view a video of a co-treatment session by 2 rehabilitation professionals and then be prompted to share thoughts or ask a question about each professional's role in the patient's care. A trigger and prompt can be tailored to address a wide variety of learning objectives, clinical scenarios, and professions. The volume of interaction is also adaptable to the needs of the activity in that students can be triggered and prompted to respond/react, ask questions, or comment in iterative cycles. The timing of interactions is also adaptable to span over a short duration such as a few days to a longer duration such as a semester. Throughout the interprofessional interaction phase, faculty facilitators can participate as much or as little as necessary to promote group engagement and ultimately adaptation and integration of ideas.

In the final debriefing phase, groups come together for synchronous debriefing using a synchronous collaborative communication technology like web conference. The goal in debriefing is to shift established frames of knowledge by eliciting students' reactions, self-examination of internal frames of reference, and realization of perspective changes. ${ }^{25}$ Formative assessment of student learning can also occur in this phase. Faculty can shape this experience in any manner they want using evidence-based frameworks such as the debriefing with good judgement framework to elicit and guide students' reflection on the IPE experience and their learning. ${ }^{25}$

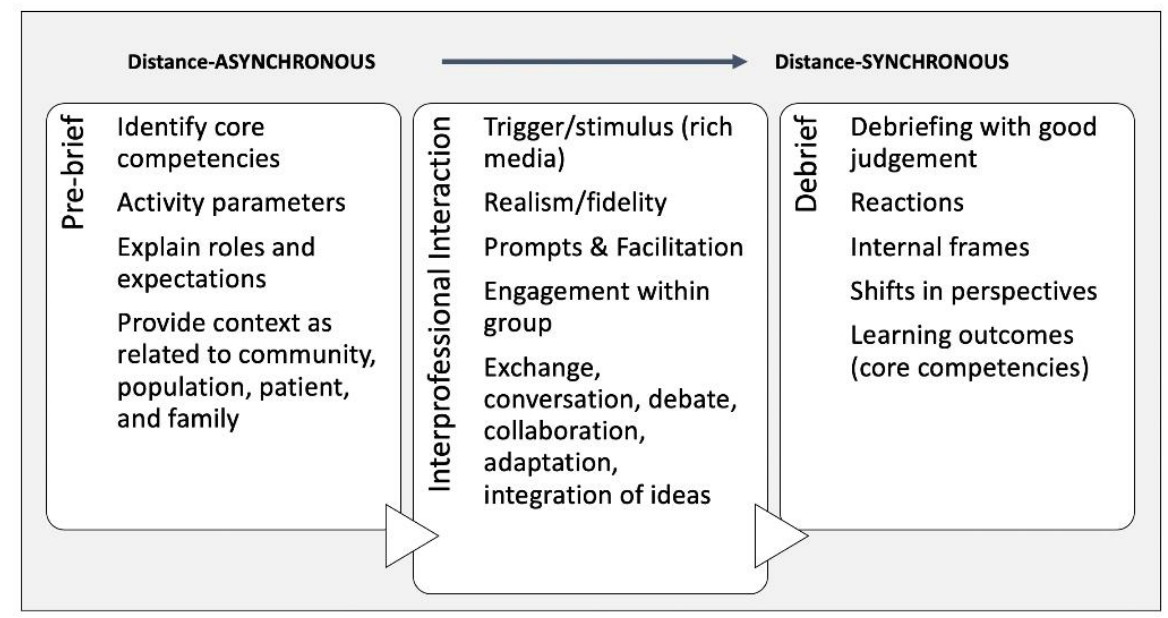

Figure 1. Hybrid interprofessional education (HIPE) model 


\section{CASE EXAMPLE OF AN IPE ACTIVITY IMPLEMENTED USING THE HIPE MODEL Planning of the Activity}

Ample preparation lead-time is important in blended learning and IPE activities. ${ }^{26}$ Collaborative planning by a team of physical therapy and physician assistant faculty began approximately 5 months before the scheduled IPE experience. The first step was to create activity objectives based on target IPEC core competencies. The planning team chose core competencies of teams and teamwork, roles and responsibilities, and interprofessional communication on which to base the learning objectives. Objectives were developed in an iterative process by the team. Agreed upon objectives were that students would a) understand how healthcare team members work collaboratively to develop a plan of care, b) understand and value the effect of collaboration on patient care, c) gain knowledge about each other's professional scope of practice, and d) improve interprofessional communication. It was agreed upon that objectives would be assessed in a low-stakes manner, using an exit survey to collect students' perceptions of achievement of activity objectives and attitudes toward interprofessional practice. Survey development is described in the outcomes section.

An outline for the professional interaction phase was developed in which students would experience interprofessional interactions regarding a patient case and engage and interact with each other as the case unfolded in 2 parts. The faculty team collaborated to create a realistic case of a patient with low back pain that would stimulate student thought and discussion in each learning objective area for both professions. Based on the case, 2 vignettes were developed which depicted the collaborative management of a patient with low back pain by a physical therapist and 2 physician assistants in outpatient settings. The vignettes were acted out by a physical therapist and a physician assistant and recorded with care taken to promote fidelity and realism in the dialogue. Each video depicted a case-consultation web-conference between the professionals as they discussed the patient's presentation and coordinated care (see Figure 2). Prompts corresponding to each vignette were created by the team to elicit student interaction through discussion. Guided reflection prompts were created to facilitate the final debriefing phase which would occur as a largegroup synchronous discussion using a web-conference application.

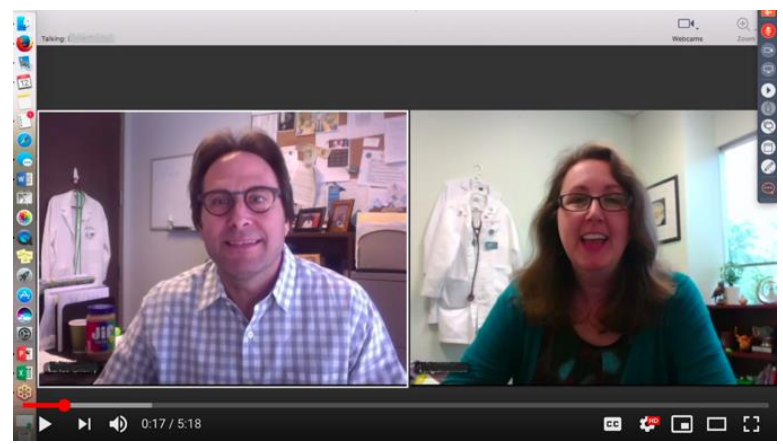

Figure 2. Case-consultation web conference

At this point, pre-briefing needs were considered. Detailed text-based pre-briefing materials were created which included a description of the activity purpose, student responsibilities and expectations, a detailed overview and timeline, and background/contextual information about the patient-case scenario. Faculty facilitators were all trained or experienced in debriefing and facilitation in IPE. Prior to the launch of the project, facilitators were oriented to this activity and given the instruction to allow student discussion to unfold with the least amount of facilitator involvement as possible to control for variability between facilitators.

\section{Implementation of the Activity}

The hybrid IPE activity occurred following a structured sequence over 8 days (see Figure 3). Students received pre-briefing materials asynchronously through a learning management system (Canvas) before the activity began. Nineteen student groups were created each with 2 SPAs, 2 or 3 SDPTs, and a physical therapist or physician assistant faculty-facilitator. Groups were assigned to an online collaborative space using a web-application (Padlet) that resembled a virtual whiteboard in which groups could collaborate via text, video, audio, images, documents, and weblinks. Each group's Padlet served as a virtual table at which they watched each case vignette and engaged with groupmates. There were 2 parts to the professional interaction phase each with a trigger video followed by discussion prompts. Students were asked to engage with each discussion prompt and respond to each other's posts. Faculty facilitators monitored the virtual tables and facilitated discussion only as needed. At the close of the professional interaction phase, students received the guided reflection questions in preparation for a synchronous debriefing discussion. On the final day, a 1-hour debriefing discussion structured around the reflection questions was conducted between both cohorts at their respective locations using a web-conferencing application.

(๖) The Internet Journal of Allied Health Sciences and Practice, 2021 


\begin{tabular}{|c|c|}
\hline \multirow{4}{*}{$\begin{array}{l}\text { D } \\
\text { D } \\
\frac{1}{O} \\
\underset{D}{D} .\end{array}$} & Day 1 \\
\hline & $\begin{array}{l}\text { - Reviewed activity parameters/objectives/expectations, introduction to the patient } \\
\text { case and context, and video tutorial on using Padlet all posted online in LMS }\end{array}$ \\
\hline & -Invitations to joint Padlet received \\
\hline & -Created Padlet account and logged in \\
\hline \multirow{7}{*}{ 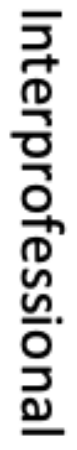 } & Day 2-4 \\
\hline & -Accessed Padlet Table and watched first trigger video \\
\hline & -Posted a video or text response to the prompt: \\
\hline & $\begin{array}{l}\text { oUsing specific examples from the video, discuss how the PA and PT demonstrated } \\
\text { skills of effective team work to provide patient-centered care. }\end{array}$ \\
\hline & Day 5 \\
\hline & -Viewed a post from a student in the other profession \\
\hline & -Responded in a video or text post to the prompt: \\
\hline \multirow{8}{*}{ 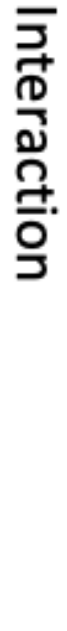 } & $\begin{array}{l}\text { What is with something new you learned or a perception/opinion/belief/value that } \\
\text { changed from viewing another's post }\end{array}$ \\
\hline & Day 6 \\
\hline & -Watched second trigger video \\
\hline & $\begin{array}{l}\text {-Addressed students of the other profession as a group in a video or text post using } \\
\text { the prompts: }\end{array}$ \\
\hline & $\begin{array}{l}\text { oTell students of the other profession something you learned about their professional } \\
\text { role, and }\end{array}$ \\
\hline & oask a question you want to know about their professional role \\
\hline & Day 7 \\
\hline & $\begin{array}{l}\text {-Answered a question posted by a student of the other profession in a video or text } \\
\text { post. }\end{array}$ \\
\hline \multirow{9}{*}{ 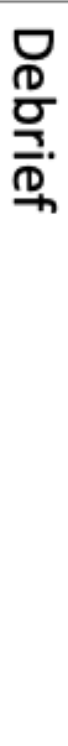 } & $\begin{array}{l}\text {-Prepared for live discussion on Day } 8 \text { by reviewing the week's conversations, and } \\
\text { reflecting on the following: }\end{array}$ \\
\hline & $\begin{array}{l}\text { oThink about something that surprised you about the interaction between the PA and } \\
\text { PT? Why did it surprise you? }\end{array}$ \\
\hline & $\begin{array}{l}\text { OWhat are the assumptions you had about the role of the other health professionals } \\
\text { before this experience? How have your assumptions been changed? }\end{array}$ \\
\hline & $\begin{array}{l}\text { OWhat do you think the benefits of interprofessional practice are now that you have } \\
\text { had this experience? }\end{array}$ \\
\hline & $\begin{array}{l}\text { oCan you see potential problems from NOT practicing with interprofessional } \\
\text { collaboration and communication? }\end{array}$ \\
\hline & Day 8 \\
\hline & $\begin{array}{l}\text {-Participated in a synchronous, web-conferenced discussion with all students and } \\
\text { some faculty facilitators }\end{array}$ \\
\hline & oPosed reflection questions to the group for discussion \\
\hline & $\begin{array}{l}\text {-Students and faculty facilitators completed online surveys to give feedback on the } \\
\text { activity }\end{array}$ \\
\hline
\end{tabular}

Figure 3. HIPE structured sequence 


\section{Student Participants}

A total of 78 students, 42 third-year SDPTs and 36 first-year SPAs, from separate satellite campuses of the same university in Florida completed the IPE activity. Student physical therapists were $57 \%$ female with a mean age of 28 years (range, 24-41 years). Student physician assistants were $69 \%$ female with a mean age of 25 years (range, 21-48 years). The SPAs attended a traditional campus-based program, whereas SDPTs attended a blended-format program in which courses contained a mix of online and faceto-face instruction. Both groups had limited prior exposure to IPE consisting only of lecture-based introduction to concepts of IPCP. Both groups had previously participated in multiple simulated learning experiences in their respective programs prior to this activity. For both student groups, the IPE activity took place as part of a course; however, while SDPTs were required to participate, SPAs participation was optional. Two SPAs and 1 SDPT did not complete the activity for unknown reasons and caused 1 group to be dispersed into other groups bringing the final count to 18 groups.

This study involved minimal risk to participants and was reviewed and granted approval by the Institutional Research Board of Nova Southeastern University (IRB \#2018-594).

\section{HYBRID IPE CASE EXAMPLE OUTCOMES}

A descriptive design and mixed methodology (quantitative and qualitative) via a survey tool was used to evaluate activity outcomes. This methodology is recommended for IPE research by the Committee on Measuring the Impact of Interprofessional Education on Collaborative Practice and Patient Outcomes for its ability to investigate the complex nature of individual and societal perceptions. ${ }^{27}$ In addition, it was consistent with the purpose of reporting outcomes in terms of the model's utility, feasibility, and ability to influence students' perceptions of and attitudes towards IPCP. ${ }^{15}$ The survey created by the investigators was based on Kirkpatrick's outcomes typology to measure outcomes at the level of reaction (Level 1) and modifications of attitudes and perceptions (Level 2a).27 Items were included to gather student feedback about the activity design and perceptions of knowledge gained in interprofessional practice, interprofessional teamwork, professional communication skills, and understanding of the other profession's role. In general, this level of outcomes assessment is sufficient to evaluate IPE outcomes for the purposes of local stakeholders including educators and accrediting bodies. ${ }^{27}$ The survey included items scored by 5-point Likert scale, semantic differential scales to capture preferences, and open-ended questions (see Figure 4). The survey was given anonymously online at the completion of the activity, and participation was voluntary.

Fifty-four participants (72\%) completed the exit survey. The response rate was $86 \%$ for SDPTs and $50 \%$ for SPAs. Survey responses yielded quantitative and qualitative data. Descriptive statistics were calculated for student demographics, Likert items, and semantic differential scales. Open-ended question responses underwent thematic analysis by 1 investigator. A second investigator confirmed the themes and analysis process through an audit of raw data, codes, groupings, and concept maps.

\section{Quantitative Survey Outcomes}

Exit survey responses illustrated students' preferences for various design elements of the hybrid IPE activity and their perceptions of learning in the activity objectives (see Table 1). With regard to learning objectives, student survey results mostly supported that objectives were met. Most students were in strong agreement that after the IPE activity they had better understanding of interprofessional practice, the importance of interprofessional teamwork, and the other profession's role. Most were in agreement that they had improved professional communication skills.

Regarding perceptions of activity design, most students strongly agreed that the collaborative web-tool, Padlet, was an appropriate and easy tool to use, using both text and video to post was easy, and they liked the mostly asynchronous format. Most students disagreed that the synchronous portion of this activity was useful. Most students agreed that they liked the activity occurring over several days, the workload was not overly burdensome, and they would like to engage in more IPE activities in general. In semantic differential scales, most showed preference for online and asynchronous delivery over face-to-face and synchronous, respectively. There was no clear preference for text versus video posting with students split on a semantic differential scale. 


\section{Survey Items}

\section{5-point Likert Scale Items}

1. Padlet was easy to use.

2. Padlet was a good tool to use for this activity.

3. Using video to post in this activity was easy.

4. Using text to post in this activity was easy.

5. I liked that the activity was mostly asynchronous (I could participate on my own schedule).

6. The synchronous activity (video-conference) was a useful part of the activity.

7. I liked that the activity was spread out over several days.

8. I better understand what interprofessional practice is because of the activity.

9. I better understand the importance of interprofessional teamwork because of the activity.

10. The activity improved my professional communication skills.

11. The activity improved my understanding of the other profession's role.

12. I liked doing IPE in this format.

13. The workload of this activity was not overly burdensome.

14. I would like to participate in more IPE activities (regardless of format).

\section{Semantic Differential Scale (1-5) Items}

15. Delivery mode: synchronous (1) vs. asynchronous (5)

16. Posting medium: text based (1) vs. video based (5)

17. Communication interface: face-to-face, same location (1) vs. online, not location dependent (5)

\section{Open-ended Questions}

18. What I liked best about the activity was:

19. What I liked least about the activity was:

20. What I got out of the activity was:

21. What I would change about the activity is:

Figure 4. Survey tool for evaluating activity outcomes

Table 1. Exit Survey Responses ( $\mathrm{N}=54)$

\begin{tabular}{|c|c|c|c|}
\hline Survey Item & Mean & Median & Range \\
\hline 1. Padlet was easy to use. ${ }^{*}$ & 4.46 & 5 & $3-5$ \\
\hline 2. Padlet was a good tool to use for this activity. ${ }^{*}$ & 4.63 & 5 & $3-5$ \\
\hline 3. Using video to post in this activity was easy. ${ }^{*}$ & 4.30 & 5 & $2-5$ \\
\hline 4. Using text to post in this activity was easy. ${ }^{*}$ & 4.78 & 5 & $3-5$ \\
\hline $\begin{array}{l}\text { 5. I liked that the activity was mostly asynchronous (I could participate on my } \\
\text { own schedule). }\end{array}$ & 4.67 & 5 & 3-5 \\
\hline $\begin{array}{l}\text { 6. The synchronous activity (video-conference) was a useful part of the } \\
\text { activity. }\end{array}$ & 2.09 & 2 & $2-4$ \\
\hline 7. I liked that the activity was spread out over several days. ${ }^{*}$ & 4.17 & 4.17 & $2-5$ \\
\hline 8. I better understand what interprofessional practice is because of the activity. ${ }^{*}$ & 4.44 & 5 & $3-5$ \\
\hline $\begin{array}{l}\text { 9. I better understand the importance of interprofessional teamwork because of } \\
\text { the activity. }\end{array}$ & 4.44 & 5 & 3-5 \\
\hline 10. The activity improved my professional communication skills. ${ }^{*}$ & 4.20 & 4 & $3-5$ \\
\hline 11. The activity improved my understanding of the other profession's role.* & 4.47 & 5 & $3-5$ \\
\hline 12. I liked doing IPE in this format.* & 4.45 & 5 & $3-5$ \\
\hline 13. The workload of this activity was not overly burdensome. * & 4.27 & 4 & $2-5$ \\
\hline
\end{tabular}

C The Internet Journal of Allied Health Sciences and Practice, 2021 


\begin{tabular}{|c|c|c|c|}
\hline 14. I would like to participate in more IPE activities (regardless of format).* & 4.20 & 4 & $2-5$ \\
\hline 15. Delivery mode ${ }^{* *}$ : synchronous (1) vs. asynchronous (5) & 4.74 & 5 & $3-5$ \\
\hline 16. Posting medium ${ }^{\star *}$ : text based (1) vs. video based (5) & 3.33 & 3 & $1-5$ \\
\hline $\begin{array}{l}\text { 17. Communication interface }{ }^{* *}: F 2 F \text {, same location (1) vs. online, not location } \\
\text { dependent (5) }\end{array}$ & 3.85 & 4 & $1-5$ \\
\hline
\end{tabular}

Note. ${ }^{*}$ Likert scale: $1=$ Strongly disagree to 5 = Strongly Agree. ${ }^{* *}$ Semantic Differential Scale ranging from 1-5.

\section{Qualitative Survey Outcomes}

Thematic analysis of the open comment data revealed 3 main themes: a) learning with and from, b) activity elements, and c) interaction (see Figure 5).

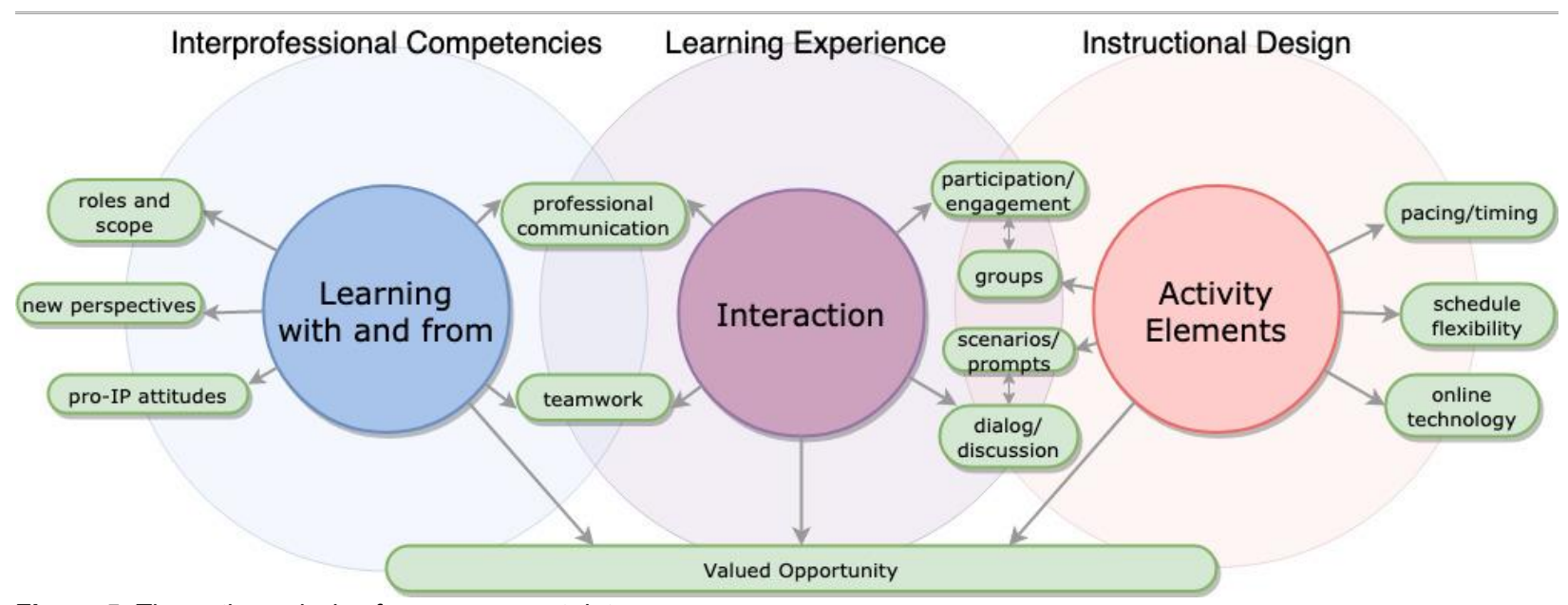

Figure 5. Thematic analysis of open comment data

\section{Learning with and from Theme}

Many comments referenced learning from, teaching others, and increasing understanding of several IPCP concepts. Students often expressed value in learning with and from (see Table 2). New knowledge was often described with words like "key," "important," and "essential." This illustrates both personal value of the knowledge and pro-interprofessional attitudes in the activity. A main area of learning was in knowledge and understanding of what the other does, professional capabilities, and similar and complementary skills as related to patient centered care. Some students expressed a desire to share information about their profession with a student from another profession and also valued learning about another profession from a fellow student. Related to professional roles and scope, students heard and saw new perspectives of a different profession and also the other student's view of them. With this came realizations that others may not understand their profession or perspective.

Professional communication was also included in what students learned with and from each other. Described as a skill, how to communicate was shown in the scenario videos, and students gained experience in their online interactions. Comments about communication were often related to its importance in professional interactions and patient centered care. The values of professionalism and respect were also associated with communication. Comments about teamwork often tied together professional roles and communication in the context of patient-centered care. In the activity, students saw teamwork role-modeled in trigger videos and worked in small groups together to complete discussion assignments. In addition, they noticed the interplay of the 2 professional roles around a common patient. Some students commented that they would have preferred to complete a collaborative problem-solving assignment, but nevertheless comments reflected understanding and valuing of teamwork in a clinical setting.

\section{Activity Elements Theme}

Many comments referenced various elements of activity design like schedule flexibility, pacing and timing, groups, online technologies, and scenarios and prompts (see Table 2). Relationships between these design elements emerged from comments. For example, many positive comments referred to schedule flexibility in students' ability to work on their "own time," "own schedule," and "when I want" because of the asynchronous format allowed by online technology. Conversely, there was dissatisfaction with the synchronous portion; however, it was not related to scheduling but rather frustration of being in a large group. While critical, student comments offered the most constructive feedback for future improvements in this area. Students expressed concern for the timing and pacing of the IPE activity in comments about the duration and pacing of asynchronous interactions and also the activity's placement in the semester and in relation to their overall course load. The activity came at the end of a semester in 
proximity to final exams, which students expressed frustrations about. With regard to the activity length, comments were not consistently in favor of a longer or shorter duration for the activity. Online technology was frequently mentioned by students with regard to being fully online, the collaborative platform used, and video, text, and web-conference modes of communication. As described previously, a relationship emerged between online technology and schedule flexibility. The online platform was generally regarded as easy to use; however, comments on functionality and technical difficulties pointed to the laboriousness of using video due to slow upload times and lack of an integrated video tool in the platform making text-based communication the preference for some. Despite technical considerations of using video, there was recognition of its power as a communication mode. In addition, technology training and support were of concern.

Small groups were a design element that elicited numerous comments being related to the number of students in groups and related to participation and engagement addressed in the Interaction Theme section (see Table 2). Students were not in agreement on the ideal numbers for the small groups in the asynchronous portion with mixed comments that groups were too small and too large. As described previously, the synchronous session also drew comments about group size with agreement that the group size then was too large to be productive. In addition to the number of students in a group, students also felt there should be more professions involved in the activity. The case scenario and prompts were at the heart of the activity design and strongly related to dialog and discussion addressed in the Interaction theme section. Scenarios drew comments highlighting their realism and use in role modeling clinical situations and behaviors. For some this was a point of criticism as the scenarios were seen as too ideal. Furthermore, prompts drew criticism for being too superficial or not enough to engage authentic discussion which is addressed further in the Interaction theme section. Some expressed a preference to have scenarios and prompts centered around solving a problem together. In addition, it was suggested that lecture would have been a better instructional method for achieving the foundational objectives that were instructed through experience and interaction in this IPE activity.

\section{Interaction Theme}

The Interaction theme emerged strongly through students plainly commenting that they liked best the interactions with students of another program (see Table 2). Appreciation and valuing the IPE interaction and interprofessional interactions in general reflects the affective learning domain. Students recognized interactions as related to professional communication and teamwork, which as described earlier were valued by students. Dialog and discussion were the primary mode of interaction and highly related to the scenarios and prompts which served as the stimuli. Dialog and discussion were also related to groups in student comments. Constructive feedback in the comments revealed that prompts may not have stimulated enough deep discussion. Related to the small groups were students' disappointed comments about group-member participation. Students referenced unequal engagement, unequal participation, and inequivalent posting and may have been a product of inequivalent requirements of the 2 groups.

\section{Valued Opportunity Subtheme}

Many relationships emerged between the themes; however, all 3 were related to one another by a valued opportunity subtheme. This subtheme was born of responses to the questions about what they liked best and what they got out of the activity. In this shared subtheme students used words like "opportunity," "chance," "available," "being able to," and "exciting" to describe aspects of the 3 themes. Students expressed eagerness to have interprofessional interaction and participate in IPE learning experiences, despite physical distance.

Table 2. Themes, Subtheme, and Student Comments

Learning With and From

Understanding Roles:

- I liked best "viewing a different clinician's perspective" (Student 13)

- What I got out of the activity was "[they] don't know much about what [we] do" (Student 32)

- "I was able to educate [the other] more clearly on our profession and learn about their profession more" (Student 17)

- I liked best "the ability to learn from the [other] students." (Student 10)

- "I learned a little bit more about the relationship between PTs and PAs, and their specific roles as it [sic] relates to patient-centered care." (Student 19)

Professional Communication:

- I liked most "Interacting with another profession that I could possibly communicate in the future regarding my pt.'s. I received additional experience in interpersonal skills" (Student 34)

- "Respect and professionalism are key to communicating with other professionals" (Student 28) 
Teamwork:

- "[T]eamwork needs to be incorporated into professional practice so that patients can get comprehensive care." (Student 54)

- I gained "understanding of the professional role of [the other] and how we can complement each other in the care of the patient." (Student 28)

- "We ... can really benefit from working with [the other] in regards to patient care." (Student 20)

Activity Elements

Schedule Flexibility:

- "I think the [synchronous] classroom discussion was difficult. Less participation per person can be had when the whole class is involved. The smaller groups worked better." (Student 7)

- "Maybe try a live meeting within the small groups." (Student 9)

Pacing and Timing:

- "Granted this is hard to get right with our schedule, but this exercise came at an inopportune time for us." (Student 36)

Activity Length:

- "If I had to make a recommendation I would say to make it longer instead of just a quick weekend assignment It might be beneficial for students of both programs to have this type of dialogue and interaction throughout the semester." (Student 19)

- "Having it spread out over several days was tough for me because I felt like I was always having to remember to work on it rather than just getting the whole thing done at once." (Student 37)

\section{Groups:}

- "In my group [some] students did not do a video so it felt less personal". (Student 21)

- I would "Involve multiple medical personnel from different medical fields." (Student 10)

Technology:

- "I had technical difficulties and I would much rather post text than a video anyway." (Student 37)

- I would "[h]ave more training for those who are unsure about technology" (Student 13)

Case Scenario:

- "I wish the activity could be more interactive and scenario based on how we both would approach a patient scenario together, and we had more questions to ask each other." (Student 17)

Instructional Method:

- "I would preface the assignment with more knowledge about the roles of PA and PT before starting this assignment. We ended up asking pretty basic questions about each other, when it should have been more [sic] a more in-depth exchange." (Student 37)

Interaction

Dialog and Discussion:

- "I wish there were more dialogue instead of just 2 or 3 responses." (Student 19)

- "The first question about teamwork didn't seem to produce authentic responses like talking about our professions did." (Student 31)

Participation:

- "I like interactions with other healthcare students. As a satellite campus we do not get that." (Student 36)

- "In person interactions would be ideal, but video/text is better than nothing!" (Student 42) 


\section{DISCUSSION}

The aims of developing the HIPE model were to improve accessibility to meaningful IPE activities by applying a blended learning approach to mitigate logistical and resource barriers. This report was intended to provide a description of the model's design, its operational principles, and provide an example of its use in a hybrid IPE activity. The HIPE model was implemented with an interprofessional group of faculty and students with outcomes reported in terms of the model's features and utility and its ability to influence students' perceptions of and attitudes towards IPCP. Quantitative and qualitative analyses of outcomes revealed that the model was feasible to implement and identified strengths and weakness in using the model which will inform future iterations. ${ }^{15}$ Analysis also suggested that using the HIPE model to deliver an IPE activity was successful in influencing student perceptions and attitudes in IPEC core competencies. ${ }^{15}$

Student comments reflected perception of improved understanding of the other profession's scope of practice (roles and responsibilities core competency) and the benefits of interprofessional collaboration (teams and teamwork core competency). Students also expressed perceived value in interprofessional communication and improvement in their communication skills through this activity. Some students' statements suggested skills of mutual respect and shared values (values/ethics for interprofessional practice core competency) were also influenced despite not being official learning objectives in this activity.

Learner-focused, faculty-focused, and organization-focused factors are recommended for effective planning and implementation of IPE activities. ${ }^{28}$ Learner-focused factors of the HIPE model include promoting interprofessional interactions, relevance, and the value of IPE.28 Strategies to optimize group dynamics are also an important learner-focused factor, but were identified by participants as a weakness in the IPE activity. ${ }^{28}$ This may have been attributable to unequal numbers of each profession in groups, inequivalent participation requirements, or potentially the differences in programs' delivery models. The synchronous large-group debriefing discussion was called into question specifically owing to the large group format which made meaningful discussion impossible for some. The HIPE model includes faculty facilitators; however, as implemented in this case, the role of the facilitators could not be examined. Facilitators were oriented to the IPE activity and case, but were instructed to facilitate discussion only if necessary, such as if the students were not participating or were getting off track. The aim of this approach was to promote student autonomy and self-directed learning and compel interaction among group members. ${ }^{6}$ Perhaps, increased facilitator involvement would have improved group dynamics in the small groups. Currently, the model does not address factors of expert facilitation or support and training. ${ }^{28}$ Faculty with small group facilitation experience and a strong understanding of IPEC core competencies may be beneficial in identifying teachable moments during the IPE activity. ${ }^{29}$ These finding highlight the need for examination of group structures, strategies for optimizing group dynamics, and aspects of facilitation as areas for future model development.

The HIPE model addresses aspects of faculty- and organization-focused factors related to implementation and key to IPE success. ${ }^{28}$ Allowing IPE activities to be performed at a distance, asynchronously and synchronously, can reduce the constraints of physical space and scheduling while accommodating larger student numbers. The model is adaptable to meet a range of needs based on available resources. The HIPE model did not alleviate the need for ample planning time in IPE required to coordinate schedules, recruit qualified and enthusiastic facilitators, and develop the activity. In the presented example IPE activity, planners took 5 months to create the IPE activity and materials. The model's technological demands may limit its accessibility and applicability for some. If faculty are not skilled in these aspects of online instruction, instructional design support may be required for creation of the online space and support during the activity. Another planning consideration was student and faculty technological literacy, orientation to the online tools used, and technical support for the activity's duration. In the presented example, much of the logistical burden of traditional IPE (physical space, scheduling) was not eliminated but rather shifted to the activity's lead-faculty. Alternative online platforms exist since the time of the pilot that may reduce the administrative workload of implementing this model. Establishing the online space and supporting students and faculty facilitators throughout the asynchronous portion involved a considerable time commitment and department-level support.

Areas of improvement for future model iterations have been described. Limitations for outcomes methodology include retrospective design, small student sample, no control for comparison, and the feedback survey used. Psychometric properties of the feedback survey were not assessed. The response rate between groups was not equal. Responses were analyzed in aggregate therefore it is not known to what extent this may have influenced survey outcomes and interpretations. Further research in this area should explore student learning outcomes not just perspectives.

\section{CONCLUSION}

The HIPE model addresses IPE delivery format to improve its feasibility. The model is flexible and not bound by temporal curricular factors. It reduces traditional logistical barriers of physical space and schedules while successfully influencing student perceptions in areas of learning objectives based on IPEC core competencies. Recently, COVID-19 has forced educators to adapt traditional teaching and learning strategies to virtual activities using online technologies. The HIPE model is a tool that educators can use to 
develop IPE competencies whenever physical proximity is not possible. Online delivery requires additional attention to issues of preparation, technological literacy of participants and facilitators, technological support, institutional support, and instructional design. Further model refinement through iterative research are needed and should include investigation of student knowledge and behavior learning outcomes when using the HIPE model.

Authors, Affiliations, and Contributions:

- Melissa J. Lazinski, PT, DPT, DHSc, Department of Physical Therapy, Nova Southeastern University. Contributions included: concept, design, supervision, resources, material, data collection, analysis and interpretation, literature search, and writing.

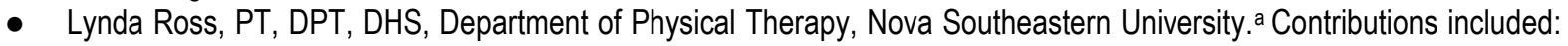
design, material, data collection, analysis and interpretation, literature search, writing, and critical review.

- Suzanne Wolf, PA, MS Department of Physician Assistant, Nova Southeastern University. Contributions included: material, data collection, and analysis and interpretation.

- Megan Finck, PA, MMS Department of Physician Assistant, Nova Southeastern University. Contributions included: material, data collection, and analysis and interpretation.

- $\quad$ Lance Cherry, PT, MPT, EdD, Department of Physical Therapy, Nova Southeastern University. Contributions included: material, data collection, and analysis and interpretation.

Acknowledgements: The authors would like to acknowledge Melissa Moran Tovin, PT, MA, PhD for her consultation in the thematic analysis.

Financial Acknowledgement: This project was funded by an Innovative Project Award received in conjunction with the Teaching and Learning Academy Fellowship of the Center for Academic and Professional Excellence (CAPE).

Conflicts of Interest: The authors confirm there are no conflicts of interest to report.

a Present affiliation: Florida Gulf Coast University, Marieb Hall, 4th floor, 10501 FGCU Blvd S, Fort Myers, FL 3396

\section{REFERENCES}

1. Reeves S, Palaganas J, Zierler B. An updated synthesis of review evidence of interprofessional education. J Allied Health. 2017;46(1):56-61 [PMID 28255597]

2. Reeves S, Pelone F, Harrison R, Goldman J, Zwarenstein M. (2017). Interprofessional collaboration to improve professional practice and healthcare outcomes. Cochrane Database Syst Rev. 2017;6(6):CD000072. doi:10.1002/14651858.CD000072.pub3 [PMID 28639262]

3. Institute of Medicine (US) Committee on the Health Professions Education Summit; Greiner AC, Knebel E, eds. Health Professions Education: A Bridge to Quality. National Academies Press (US); 2003. doi:10.17226/10681 [PMID 25057657]

4. Zorek J, Raehl C. Interprofessional education accreditation standards in the USA: a comparative analysis. J Interprof Care. 2013;27(2):123-130. doi:10.3109/13561820.2012.718295 [PMID 22950791]

5. Reeves S, Fletcher S, Barr H, et al. A BEME systematic review of the effects of interprofessional education: BEME Guide No. 39. Med Teach. 2016;38(7):656-668. doi:10.3109/0142159x.2016.1173663 [PMID 27146438]

6. Oandasan I, Reeves S. Key elements for interprofessional education. Part 1: the learner, the educator and the learning context. J Interprof Care. 2005;19 Suppl 1:21-38. doi:10.1080/13561820500083550 [PMID 16096143]

7. Oandasan I, Reeves S. Key elements of interprofessional education. Part 2: factors, processes and outcomes. J Interprof Care. 2005;19 Suppl 1:39-48. doi:10.1080/13561820500081703 [PMID 16096144]

8. World Health Organization. Framework for Action on Interprofessional Education and Collaborative Practice. World Health Organization; 2010. https://www.who.int/hrh/resources/framework_action/en/

9. Lawlis TR, Anson J, Greenfield D. Barriers and enablers that influence sustainable interprofessional education: a literature review. J Interprof Care. 2014;28(4):305-310. doi:10.3109/13561820.2014.895977 [PMID 24625198]

10. Evans SM, Ward C, Reeves S. Online interprofessional education facilitation: a scoping review. Med Teach. 2019;41(2):215-222. doi:10.1080/0142159x.2018.1460656 [PMID 29683015]

11. McCutcheon LRM, Alzghari SK, Lee YR, Long WG, Marquez R. Interprofessional education and distance education: a review and appraisal of the current literature. Curr Pharm Teach Learn. 2017;9(4):729-736. doi:10.1016/j.cptl.2017.03.011 [PMID 29233450] 
12. Mac Neill H, Reeves S, Hanna E, Rankin S. The Community of Inquiry Framework: a pertinent theory of online interprofessional education? In: Bromage A, Clouder L, Thistlethwaite J, Gordon F, eds. Interprofessional E-Learning and Collaborative Work: Practices and Technologies. IGI Global; 2010:75-89.

13. 13. Garrison, D. R., \& Kanuka, H. (2004). Blended learning: Uncovering its transformative potential in higher education. Internet High Educ. 2004;7(2):95-105. doi:10.1016/j.heduc.2004.02.001

14. Curran V, Reid $A$, Reis $P$, et al. The use of information and communications technologies in the delivery of interprofessional education: a review of evaluation outcome levels. J Interprof Care. 2015;29(6):541-550. doi:10.3109/13561820.2015 .1021002 [PMID 25955607]

15. Graham CR, Henrie CR, Gibbons AS. Chapter 2: Developing models and theory for blended learning research. In Picciano AG, Dziuban CD, Graham CR, eds. Blended Learning: Research Perspectives, Volume 2. Taylor \& Francis Group; 2013:1333

16. Interprofessional Education Collaborative. Core Competencies for Interprofessional Collaborative Practice: 2016 Update. Interprofessional Education Collaborative; 2016. https://www.ipecollaborative.org/resources.html

17. Garrison DR, Arbaugh JB. Researching the community of inquiry framework: review, issues, and future directions. Internet High Educ. 2007;10(3):157-172. doi:10.1016/j.iheduc.2007.04.001

18. Adamson K. A systematic review of the literature related to the NLN/Jeffries Simulation Framework. Nurs Educ Perspect. 2015;36(5):281-291. doi:10.5480/15-1655 [PMID 26521495]

19. Schmitt M, Blue A, Aschenbrener CA, Viggiano TR. Core competencies for interprofessional collaborative practice: reforming health care by transforming health professionals' education. Acad Med. 2011;86(11);1351. doi:10.1097/ACM.0b013e3182308e39 [PMID 22030650]

20. Garrison DR, Anderson T, Archer W. Critical inquiry in a text-based environment: computer conferencing in higher education. Internet High Educ. 2000;2(2-3), 87-105. doi:10.1016/S1096-7516(00)00016-6

21. Jeffries PR, Rodgers B, Adamson K. NLN Jeffries Simulation Theory: brief narrative description. Nurs Educ Perspect. 2015;36(5), 292-293. doi:10.5480/1536-5026-36.5.292 [PMID 26521496]

22. Young PK, Shellenbarger T. Interpreting the NLN Jeffries Framework in the context of nurse educator preparation. J Nurs Educ. 2012;51(8);422-428. doi:10.3928/01484834-20120523-02 [PMID 22624563]

23. Sabus $C$, Macauley K. Simulation in physical therapy education and practice: Opportunities and evidence-based instruction to achieve meaningful learning outcomes Simulation in physical therapy education and practice: Opportunities and evidence-based instruction to achieve meaningful learning outcomes. J Phys Ther Educ. 2013;30(1):3-13

24. Stephenson E, Poore J. Tips for Conducting the Pre-Brief for a Simulation. J Contin Educ Nurs. 2016 Aug 1;47(8):353-5. doi: 10.3928/00220124-20160715-05. [PMID: 27467309]

25. Rudolph JW, Simon R, Rivard P, Dufresne RL, Raemer DB. (2007). Debriefing with good judgment: combining rigorous feedback with genuine inquiry. Anesthesiol Clin. 2007;25(2);361-376. doi:10.1016/j.anclin.2007.03.007 [PMID17574196]

26. Hodges $\mathrm{C}$, Moore S, Lockee B, Trust T, Bond A. The difference between emergency remote teaching and online learning. Educause Review wenbsite. March 27, 2020. Accessed March 1, 2021. https://er.educause.edu/articles/2020/3/thedifference-between-emergency-remote-teaching-and-online-learning

27. Institute of Medicine. Measuring the impact of interprofessional education on collaborative practice and patient outcomes. The National Academies Press: Washington, DC; 2015

28. Reeves S, Goldman J, Oandasan I. Key factors in planning and implementing interprofessional education in health care settings. J Allied Health. 2007;36(4);231-235. [PMID 18293805]

29. Egan-Lee $E$, Baker L, Tobin $S$, et al. Neophyte facilitator experiences of interprofessional education: implications for faculty development. J Interprof Care. 2011;25(5);333-338. doi:10.3109/13561820.2011.562331 [PMID 21823882] 